Stoa

Vol. 10, no. 19, 2019, pp. 84-85

ISSN 2007-1868

\title{
MARTIN HEIDEGGER, EL INMACULADO
}

TRADUCCIÓN DE LUCILA RuVALCABA

Secretos guardados durante mucho tiempo por los sucesores de Martin Heidegger, los Cuadernos negros consignan las reflexiones del filósofo alemán (1889-1976) a partir de 1931 y eventualmente coronarán su obra. La publicación de los cuatro primeros volúmenes, entre 2014 y 2015, provocó un debate internacional ${ }^{1}$ a causa del paso explícitamente antisemita y de la apología de un nazismo incondicional.

El quinto volumen de los Cuadernos negros ${ }^{2}$ que cubre el periodo de 1948-1951 fue presentado el 21 de junio en los locales de la casa editorial Vittorio Klostermann, en Fráncfort, frente a una veintena de personas, incluidos varios miembros de la familia Heidegger, en forma de una discusión entre Peter Trawny, editor de los Cuadernos, y el periodista y escritor Lorenz Jäger. Éste último, responsable hasta el 2015 de las páginas de cultura del diario Frankfurter Allgemeine Zeitung, ha publicado asimismo con el editor austriaco de extrema derecha Karolinger una trilogía dedicada a la historia cultural de la esvástica (2006), a la francmasonería (2009) y a la teología política de los 'intelectuales judíos' (2013). Ahí leemos que son especialmente los intelectuales judíos y francmasones quienes son los corruptores de las antiguas estructuras jerárquicas y los heraldos de una democracia desarraigada.

Jäger y Trawny se ponen de acuerdo para presentar a un Heidegger inmaculado a lo largo de toda una notable acumulación de clichés: pensamiento a la vez 'audaz' y humilde, que, mientras busca sin descanso más allá de la cosificación, es decir de un vínculo de denominación a la naturaleza, es sin embargo consciente de los límites del lenguaje; pensado en continuo movimiento, explica Jäger, 'fascinante' y 'fresco'... Sin embargo, Trawnyse se sorprende que este 'artista del razonamiento' diga en este nuevo volumen que no en-

${ }^{1}$ Cf. également Francesco Alfieri et Friedrich-Wilhelm von Herrman,2018, Martin Heidegger. La vérité sur ses "Cahiers noirs", Gallimar, coll "L'infini", Paris.

${ }^{2}$ Martin Heidegger,Gesamtausgabe IV. Abteilung: Hinweise und Aufzeichnungen, Band 98, Anmerkungen VI-IX, SchwarzeHefte 1948/49-1951(edition établie par Peter Trawny, 2018) Vittorio Klosterman, Francfort. Una traducción debe estar publicada en Francia este año. 
tiende lo que él escribe: según él, es sin duda que aquí Heidegger 'se atreve a todo'. Sin embargo, en parte, esta opacidad es reivindicada en los Cuadernos negros ya que el pensador, de cara a 'el espíritu de venganza que traspasa de su bilis todo lo que es [que es parte de nuestra historia esencial]' enfrentando a la 'búsqueda de ganancias', de cara a los 'comerciantes', debe portar una 'máscara'. Lugares comunes de la tradición antisemita, omnipresentes. Sobre otro plano, la obscuridad no es el precio a pagar por la profundidad; sin embargo cae bajo el poder de un esoterismo deliberado. Para el mesías de Fribourg, querer hacerse comprender implica la ausencia del razonamiento. Y, en este nuevo Cuaderno negro, él multiplica los símbolos sibilinos: cruz, círculos, flechas, cuadrados, redondos, etc.

Ni Jäger ni Trawny evocan la persistencia con la cual relativiza los 'actos de violencia' de Adolfo Hitler; estos son 'bastante terribles', escribe él hacia 1948 pero la incapacidad de los vencedores para derrotar es 'mucho peor': dondequiera reinan 'pérdida', 'destrucción', 'bestialidad'. En cambio, ellos comentan tranquilamente el 'nomadismo' actual. Heidegger, en un seminario de 1933-1934, evocaba los 'nómadas semitas' que no tienen acceso 'a nuestro espacio alemán' inaptos para comprender verdaderamente la noción de patria, encarnaciones de la falta de arraigo; sin embargo, sin arraigo, no morimos, 'estiramos la pata'. Es lo que él declaraba al momento de sus conferencias de Bremen en 1949. ${ }^{3}$

\section{SIDONIE KELLERER}

Reciente publicación: "Sein und Zeit: ein Buch für Alle und Jeden?", en: Meiner, F., 2018, 'Sein und Zeit' neu verhandelt hg. v. T. Bender u. M. Heinz, Hamburg.

Recibido 8 de septiembre de 2018 Aceptado 25 de septiembre de 2018

\footnotetext{
${ }^{3}$ Martin Heidegger,Gesamtausgabe. III. Abteilung: Unverröffentliche Abhandlungen. VorträgeGedachtes. Band 79. Bremer und FreiburgerVorträge (edición realizada por Petra Jaeger, 1994), Vittorio Klostermann, Francfort.
} 